\title{
Desigualdade de renda em tempos de pandemia: uma análise da decomposição do Índice de Gini a partir da PNAD Covid19
}

Income inequality in pandemic times: an analysis of the decomposition of the Gini Index from PNAD COVID19

\section{Cassiano José Bezerra Marques Trovão* Fabrício Pitombo Leite ${ }^{\dagger}$}

\begin{abstract}
Resumo
Esse artigo tem por objetivos: 1) avaliar os primeiros impactos da pandemia sobre a desigualdade de renda no Brasil a partir da PNAD COVID19 do IBGE; 2) apresentar as contribuições das distintas fontes de renda para a composição do Índice de Gini, evidenciando seu caráter de progressividade ou regressividade para o indicador; 3) quantificar o impacto do auxílio emergencial para a evolução da desigualdade de renda nesse período; 4) mensurar, a partir de cinco cenários, o impacto de uma possível alteração nos valores do auxílio emergencial, pressupondo sua continuidade em um futuro próximo ou sua extinção completa. Os resultados apontam que as proteções sociais, permanente e emergencial, mostraram-se fundamentais para a queda da desigualdade. Mais que isso, sua extinção ou a redução dos valores base, por elas definidos, provocarão um aumento da concentração de renda.
\end{abstract}

Palavras-chave: Pandemia; Desigualdade de renda; PNAD COVID19; Brasil.

Classificação JEL: D31; E64.

\begin{abstract}
This article aims to: 1) assess the first impacts of the pandemic on income inequality in Brazil from the PNAD COVID19 of IBGE; 2) present the contributions of the different sources of income to the composition of the Gini Index; showing its progressive or regressive character; 3) quantify the impact of emergency aid for the evolution of income inequality in this period; 4) measure, from five scenarios, the impact of a possible change in the values of the emergency aid, assuming its continuity in the near future or its complete extinction. The results show that social protection, permanent and emergency, proved to be fundamental for the reduction of inequality. More than that, its extinction or the reduction of the base values, will cause an increase in the concentration of income.
\end{abstract}

Keywords: Pandemic; Income inequality; PNAD COVID19; Brazil.

JEL Classification: D31; E6

\footnotetext{
"Professor do Departamento de Economia e do PPECO e pesquisador do Grupo de Pesquisa em Economia Política do Desenvolvimento (GEPD) e do Núcleo de Análise Econômica Multissetorial, Estratégica e Conjuntural - NEMEC da Universidade Federal do Rio Grande do Norte. E-mail: c_trovao@yahoo.com.br.

† Bacharel (UFBA, 2005), Mestre (UNICAMP, 2008) e Doutor (UNICAMP, 2012) em Ciências Econômicas, atualmente é professor adjunto da Universidade Federal da Bahia. E-mail: fabriciopleite@ufrnet.br
} 


\section{Introdução}

A pandemia provocada pelo Sars-Cov-2, um tipo de coronavírus de elevado grau de contágio e sem remédio ou vacina conhecidos, implicou a eclosão de uma severa crise que se inicia no âmbito sanitário, levando à saturação dos sistemas públicos de saúde, e que tem seu escopo ampliado em direção a outras dimensões, transformando-se em uma crise econômica e social. A redução da atividade econômica decorrente das necessárias medidas de isolamento social provocou um expressivo choque negativo de oferta que logo se transfigurou para um choque de demanda, provocado pela redução dos investimentos e, principalmente, pelo consumo das famílias, que viram sua renda reduzir abruptamente, após a perda de milhões de postos de trabalho ${ }^{1}$.

A resposta dada por diversos governos ao redor de todo o mundo foi no sentido de proteger a classe trabalhadora e a renda da população mais vulnerável². No Brasil, após elevada pressão popular e disputa política no Congresso Nacional, à revelia da equipe econômica que permaneceu buscando seguir a cartilha da austeridade fiscal ${ }^{3}$, conquistou-se por meio da MP no $937^{4}$ um auxílio emergencial monetário, com recursos do Tesouro Nacional, no valor de $\mathrm{R} \$ 600,00$, sendo R \$1.200,00 para "a mulher provedora de família monoparental", destinado a atender um público-alvo composto por: trabalhadores informais, microempreendedores individuais, desempregados e beneficiários do Programa Bolsa Família.

Uma das questões que se apresentam, nesse contexto, diz respeito aos efeitos dessa crise sobre a desigualdade. Apesar de se reconhecer que não se trata simplesmente de uma desigualdade, mas de múltiplas dimensões desse fenômeno e, portanto, de desigualdades, a pandemia tem tornado explícita a elevada desigualdade de renda, marca histórica da sociedade brasileira. Assim, defende-se que, para além dos desafios colocados por essa pandemia do ponto de vista da saúde da população, a crise do coronavírus afetou, também, a renda da classe trabalhadora bem como sua

\footnotetext{
${ }^{1}$ Ver IMF (2020).

${ }^{2}$ Ver Seção 1.3 "An unprecedented policy response by countries" em OECD (2020).

${ }^{3}$ Além de propor um valor de apenas $\mathrm{R} \$ 200,00$ para a população mais vulnerável do Brasil, o governo insistiu, inicialmente, na continuidade das reformas e do ajuste das contas públicas enquanto melhor resposta para a crise da COVID19. Ver FSP (2020a e 2020b).

${ }^{4}$ A Medida Provisória no 937, de 2 de abril de 2020, destinava R\$98,2 bilhões para o pagamento de três parcelas ao que se estimava ser um público-alvo de aproximadamente 51,4 milhões de beneficiários. Posteriormente, percebeu-se que a grande demanda pelo auxílio tornaria os recursos insuficientes e, então, lançou-se a Medida Provisória no 956, de 24 de abril de 2020, que destinou mais $\mathrm{R} \$ 25,72$ bilhões. A Lei $\mathrm{n}^{\circ} 13.982$, de 2 de abril de 2020 regulamentou essas medidas, definindo o público-alvo. Ver Brasil (2020a, 2020b, 2020c).
} 
concentração, impactando diretamente sua capacidade de acesso a bens e serviços de primeira necessidade e sua própria condição de vida.

Nesse sentido, os objetivos desse artigo são: 1) fazer uma avaliação dos primeiros impactos da pandemia sobre a desigualdade de renda no Brasil entre maio e julho de 2020, a partir dos dados divulgados pela nova Pesquisa Nacional por Amostra de Domicílios COVID19 (PNAD COVID19) do Instituto Brasileiro de Geografia e Estatística (IBGE); 2) apresentar as contribuições das distintas fontes de renda para a composição do Índice de Gini, evidenciando seu caráter de progressividade ou regressividade para o indicador; 3) quantificar o impacto do auxílio emergencial para a evolução da desigualdade de renda no país nesse período; 4) mensurar, a partir de cinco hipóteses, o impacto de uma possível alteração nos valores do auxílio emergencial, pressupondo sua continuidade em um futuro próximo ou sua extinção completa.

artigo é composto por mais três seções, além dessa breve introdução. A primeira apresenta as definições metodológicas a respeito da decomposição do Índice de Gini e dos cenários e hipóteses que poderiam afetar o valor do auxílio emergencial e, por consequência, a desigualdade de renda em um futuro próximo. A segunda traz a discussão dos principais resultados encontrados para os meses de maio a julho de 2020 para o Brasil. Já, na última seção, procura-se apresentar algumas considerações a respeito do estudo, apontando para os desafios a serem enfrentados em um cenário pós-pandemia.

\section{Metodologia e base de dados}

Com microdados mensais, publicados a partir do mês de maio, o IBGE (2020a e 2020b) disponibilizou sua "primeira pesquisa divulgada com o selo de Estatística Experimental". No entanto, deve-se registrar uma ressalva para os resultados aqui apresentados: "A PNAD COVID19 está sendo apresentada como Estatística Experimental pois ainda está sob avaliação, ou seja, ainda não atingiu um grau completo de maturidade em termos de harmonização, cobertura ou metodologia" (IBGE, 2020b, p. 4).

Feito esse alerta e, dado o objetivo de se calcular a desigualdade para a renda domiciliar per capita (RDPC) de todas as fontes, a comparação entre os diferentes meses da própria PNAD COVID19 exigiu, inicialmente, uma agregação por domicílio e, posteriormente, a divisão pelo número de moradores das seguintes fontes de rendimento: i) Todos os trabalhos em dinheiro (C011A12); ii) Aposentadorias e pensões (D0013); iii) Doação, pensão alimentícia ou mesada (D0023); iv) Bolsa Família (D0033); v) BPC-LOAS (D0043); vi) Auxílio Emergencial 
(D0053); vii) Seguro-desemprego (D0063); e viii) Aluguel, arrendamento, aplicações financeiras etc. (D0073). Considerou-se, portanto, a soma dessas oito parcelas como a RDPC de todas as fontes. Nesse procedimento de agregação por domicílios, os rendimentos de todos os trabalhos (i) dos diferentes moradores foram somados, enquanto os rendimentos de outras fontes (ii a viii) aparecem como uma informação disponibilizada pelo próprio IBGE na forma de somatório dos valores recebidos por todos os moradores.

O cálculo do índice de Gini para essa RDPC e sua posterior decomposição pelas oito parcelas de rendimento seguiu a metodologia apresentada por Hoffmann (2009). Para tal, foram calculadas as razões de concentração para cada uma das parcelas, que consistem, basicamente, em medidas similares ao índice de Gini, porém computadas para cada parcela, preservando-se a ordenação original definida para a RDPC de todas as fontes. Essas razões de concentração, ponderadas por suas respectivas participações na renda, resultam, por definição, no índice de Gini total para a RDPC, ou seja, pode-se verificar que o índice de Gini é uma média ponderada das oito razões de concentração calculadas.

Como medida de progressividade das parcelas, ainda segundo Hoffmann (2009), toma-se a diferença entre o índice de Gini e a razão de concentração de cada parcela, o que resulta em resultados positivos para parcelas progressivas (tão mais elevados quão menores ou mais negativas sejam as razões de concentração) e negativos para parcelas regressivas, caso em que a razão de concentração é superior ao índice de Gini. Essas medidas seguem a proposta de Lerman e Yitzhaki (1985, 1994).

Para a confecção dos cenários propostos enquanto hipóteses de alterações nos valores do auxílio emergencial, os rendimentos recebidos por domicílio, conforme captados pela PNAD COVID19, de $\mathrm{R} \$ 600,00$ e seus múltiplos mais frequentes ( $\mathrm{R} \$ 900,00 \mathrm{R} \$ 1200,00, \mathrm{R} \$ 1800,00, \mathrm{R} \$ 2400,00, \mathrm{R} \$ 3000,00$ ), foram substituídos por diferentes valores que, nos distintos cenários, representariam alterações prováveis no valor base do auxílio e em seus múltiplos, a saber, $\mathrm{R} \$ 500,00$; $\mathrm{R} \$ 400,00$; e $\mathrm{R} \$ 300,00$. As exceções foram os cenários em que os recebimentos assumiriam um valor igual à média do PBF ou zero, no caso de uma possível extinção do auxílio emergencial. Nesses casos, todos os múltiplos foram substituídos pela referida média ou por zero, respectivamente. 


\section{Discussão dos resultados}

Os dados da PNAD COVID19 apontam para um processo de deterioração do mercado de trabalho no Brasil, decorrente da crise do coronavírus que se manifesta: 1) na redução da taxa de participação na força de trabalho e do nível de ocupação até julho, com relativa recuperação a partir de agosto; 2) elevação da taxa de desocupação ao longo de todo o período, que subiu de 10,7\% em maio para 14,2\% em novembro; 3) redução da informalidade entre maio e julho, com relativa elevação a partir de agosto, atingindo 34,5\% do total de ocupados em novembro; e 4) expansão da subutilização da força de trabalho até julho, quando mais de 31 milhões de pessoas se encontravam subocupadas, desocupadas, desalentadas, ou haviam procurado trabalho mas não estavam aptas a assumir o posto de trabalho na semana de referência, e posterior redução, atingindo 27,7 milhões de pessoas em novembro (Ver Tabela 1).

As pesquisas realizadas entre maio e julho apontam que o número de trabalhadores informais se reduziu de, aproximadamente, 29,3 milhões para 27,4 milhões de pessoas, o que representa uma redução da taxa de informalidade de $34,7 \%$ para $33,6 \%$. Essa queda da informalidade poderia parecer, à primeira vista, uma relativa melhora no mercado de trabalho. Porém, esse foi o segmento mais afetado pela pandemia e pelas medidas de distanciamento social, que levaram a uma redução do consumo das famílias de bens e serviços por esses trabalhadores ofertados. A pandemia trouxe impactos negativos para milhões de trabalhadores nessa condição, que perderam suas fontes de trabalho e renda.

A partir de julho, o emprego informal voltou a se expandir (mais de 1,8 milhão de novos postos de trabalho foram gerados nesse segmento) o que acabou por refletir um aumento da taxa de informalidade para 34,5\% do total em novembro. Essa relativa recuperação a partir de julho se deve ao relaxamento de algumas medidas de isolamento social por todo o país e ao retorno de algumas atividades que favoreceram a expansão da ocupação informal.

Um dos fenômenos que mais se destacam enquanto reflexo da crise do coronavírus é a redução do nível de ocupação (ocupados em relação à população em idade de trabalhar). Entre maio e junho o nível de ocupação passou de 49,7\% para 47,9\%, momento em que atinge seu mínimo. A relativa recuperação posterior ainda não se mostrou suficiente para reverter $\circ$ fato de a crise ter feito o país apresentar uma situação em que mais da metade de sua população em idade de trabalhar se encontra fora da força de trabalho ou desocupada. 
Tabela 1. Indicadores de mercado de trabalho para o Brasil (maio-novembro, 2020)

\begin{tabular}{|c|c|c|c|c|c|c|c|}
\hline Indicador & Maio & Junho & Julho & Agosto & Setembro & Outubro & Novembro \\
\hline $\begin{array}{l}\text { Taxa de participação na força de } \\
\text { trabalho (\%) }\end{array}$ & 55,6 & 56,0 & 55,1 & 55,8 & 56,5 & 57,4 & 57,8 \\
\hline Nível da ocupação (\%) & 49,7 & 49,0 & 47,9 & 48,2 & 48,6 & 49,3 & 49,6 \\
\hline Taxa de desocupação (\%) & 10,7 & 12,4 & 13,1 & 13,6 & 14,0 & 14,1 & 14,2 \\
\hline $\begin{array}{l}\text { Proxy da taxa de informalidade das } \\
\text { pessoas ocupadas (\%) }\end{array}$ & 34,7 & 34,8 & 33,6 & 33,9 & 34,2 & 34,5 & 34,5 \\
\hline $\begin{array}{l}\text { Proxy da subutilização da força de } \\
\text { trabalho (mil pessoas) }\end{array}$ & 28.584 & 29.638 & 31.185 & 30.436 & 29.465 & 28.267 & 27.690 \\
\hline
\end{tabular}

Os dados apontam, também, para um processo de expansão do contingente de pessoas fora da força de trabalho, que chegou a atingir 76,5 milhões em julho, puxado pelo desalento decorrente do aumento do número de pessoas que não procuraram trabalho por conta da pandemia ou por falta de trabalho na localidade onde residiam. A partir de agosto, as pessoas voltaram a procurar trabalho, provocando uma redução da população fora da força de trabalho e um aumento da desocupação, que reforçou o movimento de elevação da taxa de desocupação (Tabela 1). ${ }^{5}$

Os primeiros dados divulgados pelo IBGE, referentes aos efeitos da pandemia para o mercado de trabalho, chegaram a mostrar que mais de 16,5 milhões de pessoas encontravam-se afastadas do trabalho devido ao distanciamento social no início de maio. Com o relaxamento das medidas de isolamento e a relativa recuperação da atividade econômica em alguns setores específicos como o comércio e os serviços, esse contingente se reduziu significativamente atingindo, em novembro, um patamar de 2,7 milhões de pessoas.

Apesar de a pandemia ter afetado fortemente o mercado de trabalho, parte significativa da composição da renda das famílias brasileiras manteve-se ancorada na proteção social de caráter permanente, composta por programas como: Aposentadorias e Pensões do INSS (inclusive rural), o Benefício de Prestação Continuada (BPC) e o Programa Bolsa Família. Esse aparato de proteção social constituído criou um colchão de amortecimento para os efeitos perversos que a pandemia trouxe para a renda oriunda do mercado de trabalho. Ademais, essa proteção permanente veio a se somar aos recursos destinados ao pagamento do auxílio emergencial. É com esse processo em mente que se pretende explorar as

\footnotetext{
${ }^{5}$ Ver IBGE (2020a; 2020b; 2020c; 2020d; 2020e; 2020f).
} 
informações da PNAD COVID19, a respeito dos impactos para a desigualdade de renda corrente no Brasil.

Antes de apresentar os resultados, é necessário que se faça uma ressalva quanto aos limites que essa pesquisa possui para a mensuração da desigualdade em sua dimensão associada à renda. Essa limitação reside no fato de a pesquisa subestimar as rendas oriundas do capital (mobiliário e imobiliário). Apesar de possuir uma pergunta sobre rendimentos de outras fontes como: aluguel, arrendamento, previdência privada, bolsa de estudos, rendimentos de aplicação financeira etc., tais dados são subestimados, refletindo um baixo peso relativo no total da renda (Ver Gráfico 1).

\section{Gráfico 1. Peso relativo de cada parcela no total da renda segundo suas distintas fontes (\%) no Brasil, de maio a novembro de 2020}

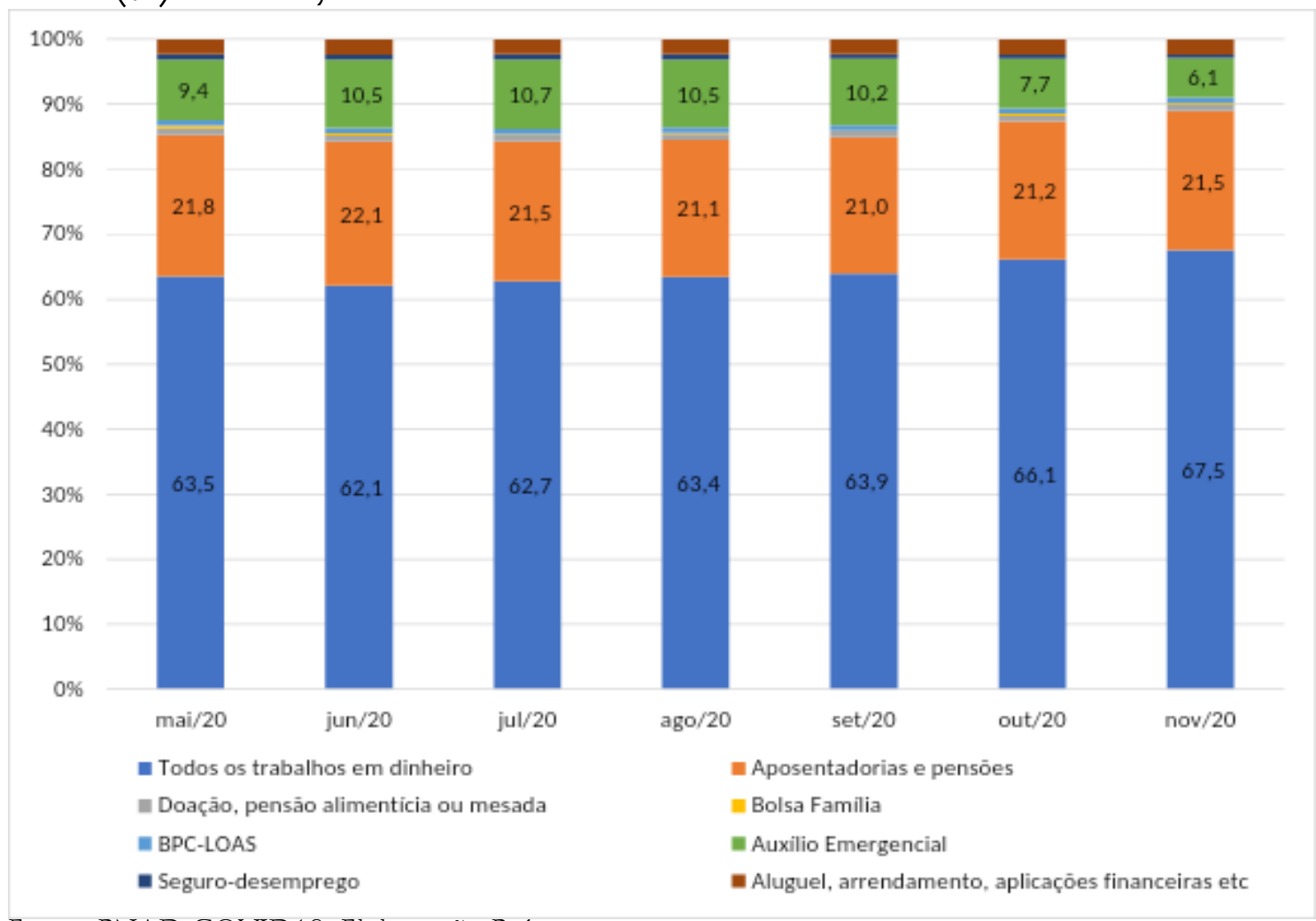

Fonte: PNAD COVID19. Elaboração Própria.

Nota-se que, apesar dos fortes e negativos impactos sobre o mercado de trabalho, esse se manteve como a principal fonte geradora de renda para a população brasileira, ainda que seu peso tenha se reduzido entre maio e junho. No entanto, é importante que se observe que o auxílio emergencial cumpriu um papel fundamental ao assegurar uma relativa sustentação da massa de renda das famílias. Os recursos destinados ao pagamento do auxílio chegaram a representar 10,7\% da massa de renda de todas as fontes em julho de 2020. De agosto em diante, o peso relativo do auxílio emergencial na massa de renda reduziu-se para 10,2\%, em setembro, para 
7,7\%, em outubro e para 6,1\% em novembro. Esse movimento decorre de dois fatores básicos: a redução do valor do benefício de $\mathrm{R} \$ 600,00$ para $\mathrm{R} \$ 300,00$ a partir de outubro; e a relativa elevação do nível de ocupação, que ampliou a massa de renda do trabalho nesses meses.

Somando-se a proteção social permanente e a emergencial, os recursos oriundos de fora do mercado de trabalho passaram a representar aproximadamente $1 / 3$ de todos os rendimentos auferidos pelas famílias brasileiras, indicando a relevância do papel do Estado para a composição e a sustentação da renda, especialmente em momentos de crise.

A resposta para o que aconteceu com a apropriação da renda separada por intervalos decílicos pode ser vista na Tabela 2. Os dados apontam para uma relativa melhora na distribuição do rendimento domiciliar per capita de todas as fontes, entre maio e agosto, que decorreu da elevação da renda apropriada pelos $20 \%$ mais pobres, que passou de $3,9 \%$ para $4,7 \%$, e da queda da renda apropriada pelos $20 \%$ mais ricos, que passou de 55,2\% para 53,9\%. A partir de setembro, o que se observa é uma reversão desse processo: a parcela apropriada pelos $20 \%$ mais pobres passou de 4,6\%, em setembro, para 3,7\%, em novembro; e a dos $20 \%$ mais ricos se ampliou de 53,3\% para 54,8\%, nesse mesmo período. Esse movimento está diretamente associado ao auxílio emergencial, que cumpriu um papel relevante na proteção dos mais vulneráveis, sustentando a massa de renda na base da distribuição, nos primeiros meses da crise decorrente da pandemia. Porém, sua redução pela metade, em outubro, provocou uma reconcentração da renda, em um movimento associado à lenta recuperação do mercado de trabalho.

Tabela 2. Participação na massa de rendimento domiciliar per capita de todas as fontes no Brasil, segundo intervalos decílicos, de maio a novembro de 2020

\begin{tabular}{cccccccc}
\hline Décimos & Maio & Junho & Julho & Agosto & Setembro & Outubro & Novembro \\
\hline 1 & 1,3 & 1,3 & 1,6 & 1,6 & 1,6 & 1,3 & 1,1 \\
2 & 2,6 & 3,1 & 3,0 & 3,1 & 3,0 & 2,7 & 2,6 \\
3 & 3,9 & 3,9 & 3,9 & 4,1 & 4,1 & 3,7 & 3,7 \\
4 & 4,8 & 4,9 & 5,0 & 5,0 & 5,0 & 4,6 & 4,6 \\
5 & 6,0 & 5,5 & 6,1 & 6,1 & 6,1 & 6,3 & 6,0 \\
6 & 7,2 & 7,6 & 7,2 & 6,9 & 6,3 & 6,5 & 7,0 \\
7 & 8,7 & 8,7 & 8,2 & 9,1 & 9,2 & 9,3 & 9,1 \\
8 & 10,3 & 10,9 & 11,3 & 10,4 & 11,3 & 11,4 & 11,1 \\
9 & 15,9 & 15,4 & 15,2 & 15,1 & 14,3 & 15,5 & 15,7 \\
10 & 39,3 & 38,7 & 38,4 & 38,8 & 39,0 & 38,8 & 39,1 \\
\hline Total & 100,0 & 100,0 & 100,0 & 100,0 & 100,0 & 100,0 & 100,0 \\
\hline Fonte: PNAD COVID19. Elaboração Própria. & & & &
\end{tabular}


A esse respeito, dois comentários podem ser feitos: 1) a concentração da renda corrente no país permanece extremamente elevada (os 10\% mais ricos se apropriam de parcela superior àquela apropriada pelos $70 \%$ mais pobres da população); e 2) o movimento de redução da concentração da renda corrente possibilitado pelo auxílio emergencial se mostrou limitado, uma vez que seu efeito foi revertido abruptamente após a redução do valor do benefício, a partir de outubro.

Do ponto de vista da distribuição pessoal da renda, o Índice de Gini para o rendimento de todas as fontes caiu $-3,7 \%$ entre maio e agosto, manteve-se estável entre agosto e setembro, e passou a subir a partir de outubro, momento em que o auxílio emergencial foi reduzido pela metade ${ }^{6}$. Esse movimento é reforçado pela redução da contribuição progressiva do auxílio emergencial a partir de outubro (Ver Gráfico 2).

A tendência de queda recente da desigualdade de renda corrente no Brasil esteve intimamente associada à manutenção da proteção social permanente, especialmente aquela oriunda do Programa Bolsa Família, e à proteção social emergencial, destinada aos informais e mais vulneráveis. A principal evidência dessa constatação está na reversão observada dessa tendência a partir de outubro.

${ }^{6}$ Cabe destacar que o efeito da queda pela metade do auxílio emergencial é apenas parcial, uma vez que existem muitas pessoas que ainda receberam parcelas no valor de $\mathrm{R} \$ 600,00$. 
Gráfico 2. Contribuição absoluta para a composição do Índice de Gini para a renda pessoal no Brasil, segundo fontes de renda (maio-novembro, 2020)

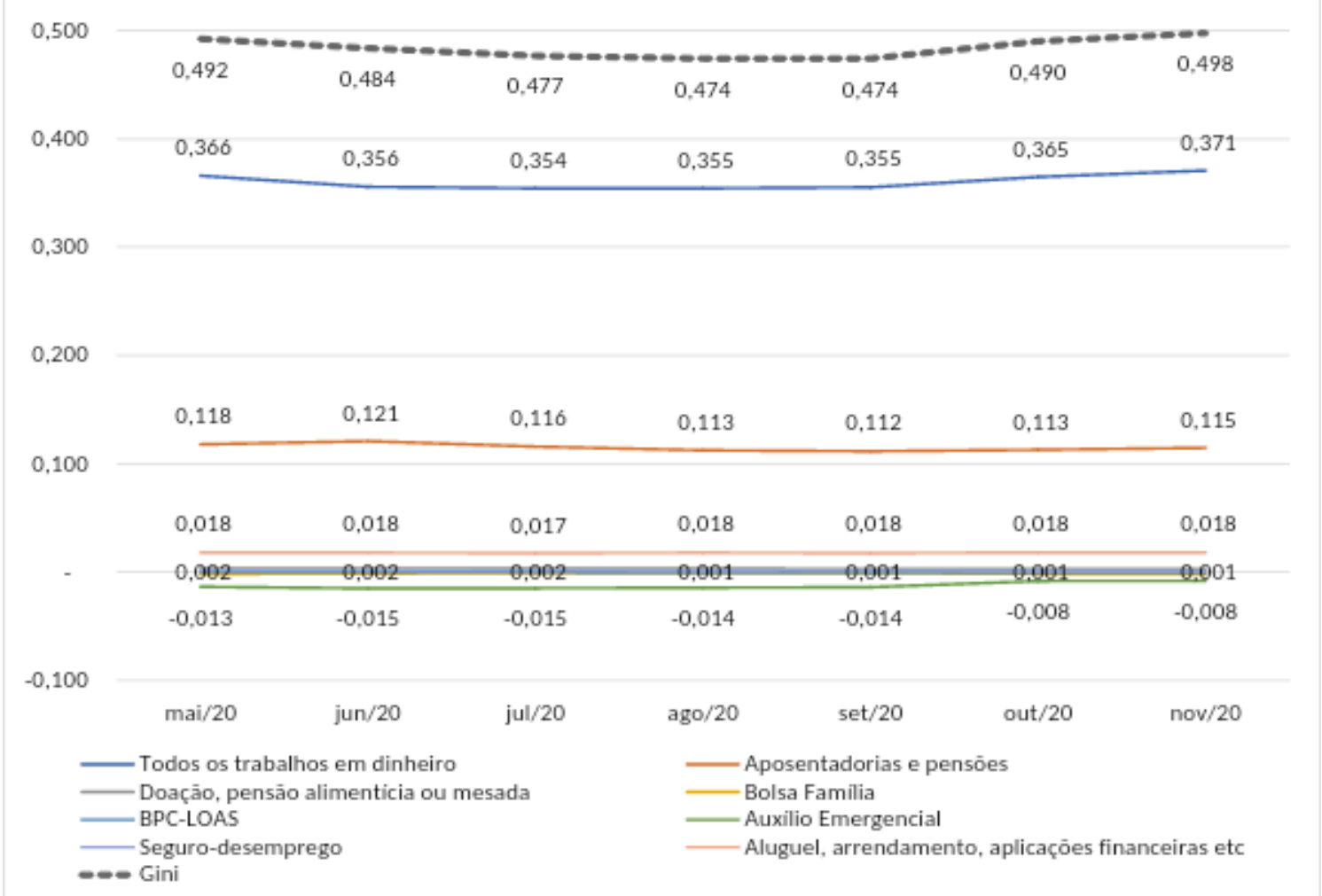

Fonte: PNAD COVID19. Elaboração Própria.

Essa argumentação pode ser reforçada pela análise da progressividade de cada fonte de renda para a composição dos índices nos meses analisados (Ver Gráfico 3). De acordo com a decomposição do Gini por fonte de renda, aquelas associadas à Proteção Social mostraram-se significativamente mais progressivas, o que quer dizer que elas contribuem para a redução da desigualdade.

As fontes de maior progressividade são justamente aquelas que atenuam a condição de vulnerabilidade da população da base da distribuição, ou seja, os beneficiários do Programa Bolsa Família e os do auxílio emergencial, que os inclui, mas que, também, destina-se aos desocupados, aos trabalhadores informais e aos microempreendedores individuais. 
Gráfico 3. Progressividade para o Índice de Gini para a renda pessoal no Brasil, segundo fonte de renda (maio-novembro, 2020)

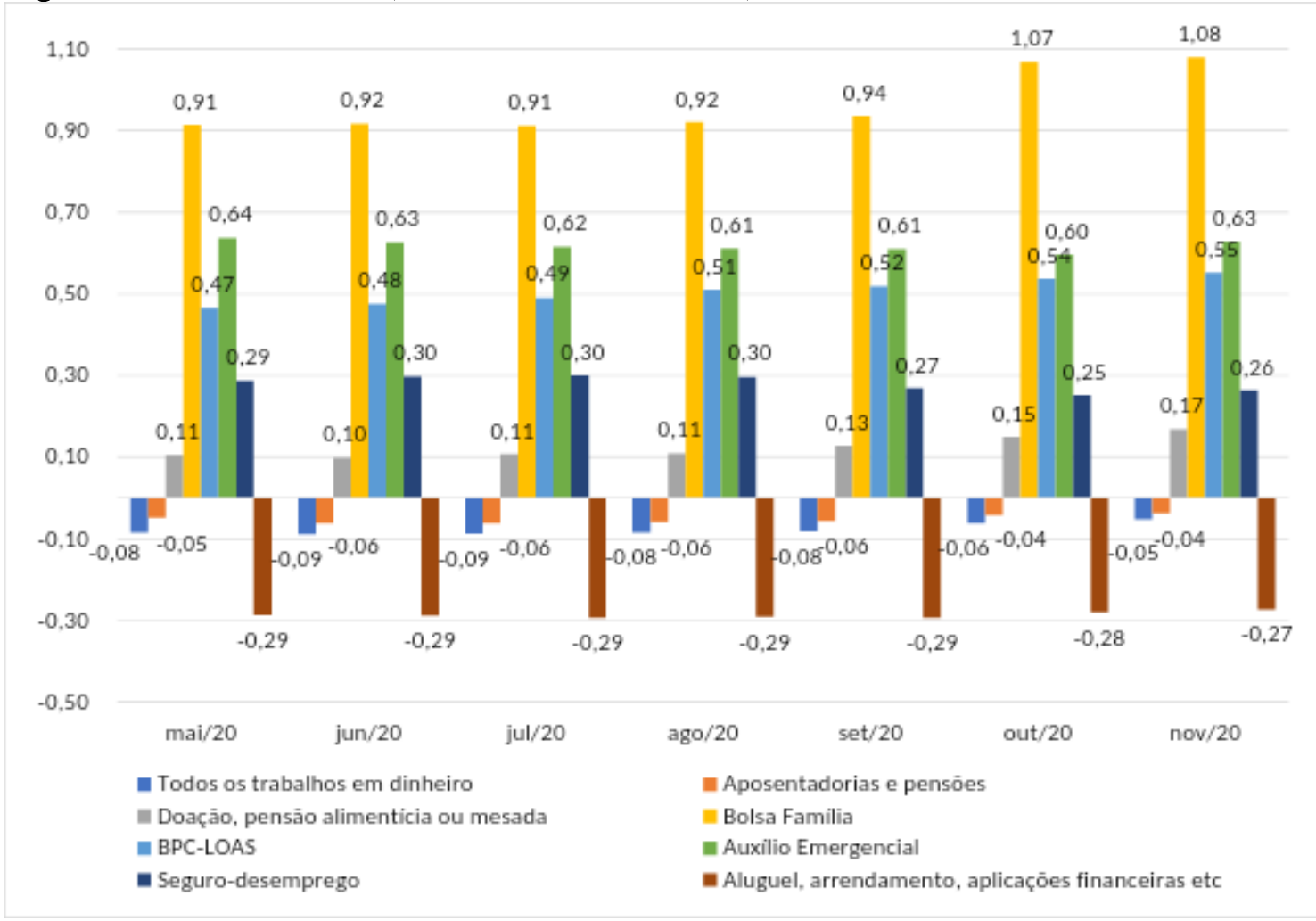

Fonte: PNAD COVID19. Elaboração Própria.

Por fim, resta responder o que poderia acontecer caso fossem alterados os valores definidos pela proteção social emergencial. Os dados para o Índice de Gini nos cinco cenários traçados para o valor base ( $\mathrm{R} \$ 500,00 ; \mathrm{R} \$ 400,00 ; \mathrm{R} \$ 300,00^{7}$; valor igual à média do benefício do PBF; e extinção do auxílio emergencial), comparativamente ao cenário inicial de $\mathrm{R} \$ 600,00$ definido pela MP 937, apontam para uma elevação imediata da desigualdade de renda, no momento da imposição dos novos valores.

As estimativas indicam que reduzir o valor do benefício, aventando-se a possibilidade de essa proteção social emergencial tornar-se permanente, tenderia a produzir uma piora da distribuição pessoal da renda ${ }^{8}$. Ao menos parcialmente ${ }^{9}$, esse argumento ganha força pela reversão observada da tendência de redução da

\footnotetext{
7 A partir de outubro, o cenário três sofreu uma adaptação para captar o efeito combinado do recebimento por parte da população de parcelas no valor de $\mathrm{R} \$ 600,00 / \mathrm{R} \$ 1.200,00$ - referentes aos pagamentos descasados no tempo - e de $\mathrm{R} \$ 600,00 / \mathrm{R} \$ 300,00$. Para tanto, manteve-se a mesma renda para o caso em que a mulher (A003) era responsável pelo domicílio (A001A) e efetuou-se a redução para $\mathrm{R} \$ 600 / 300$ caso contrário.

${ }^{8}$ Vale ressaltar que essas estimativas foram realizadas preservando-se a cobertura do auxílio emergencial observada na PNAD COVID19.

${ }^{9}$ Parcialmente, pois muitos beneficiários do auxílio ainda receberam a parcela no valor de $\mathrm{R} \$ 600,00$ em outubro.
} 
desigualdade experimentada a partir de outubro, momento em que se reduziu o valor do benefício pela metade ${ }^{10}$.

Como esse é um dos cenários traçados, nota-se que, já em maio, o índice de Gini para o valor reduzido pela metade teria sido 6,8\% maior que o efetivo e, em julho, 7,7\% maior. A partir de agosto, inicia-se um processo de convergência entre a curva estimada para o valor reduzido à metade (reta amarela) e aquela estimada para Gini efetivo (reta pontilhada), estabelecendo uma diferença que passou dos 7,7\%, em julho, para 2,4\%, em novembro ${ }^{11}$ (Ver Gráfico 4).

Os dados apontam para um movimento em que a estimativa do valor reduzido à metade funciona como uma proxy da realidade provável que o país encontrará, uma vez mantido o corte do auxílio emergencial, isto é, um nível de desigualdade aumentado para o qual o valor do Gini efetivo está convergindo.

De modo análogo, os outros cenários traçados, isto é, aqueles em que o auxílio é extinto e/ou que se leva a cabo uma política de renda mínima, que poderia assumir a forma de um Bolsa Família expandido para contemplar o público-alvo do auxílio emergencial, apontam para um mesmo processo. Neste, o Gini efetivo assume uma trajetória de convergência na direção das proxys, em direção a uma realidade bastante provável em que a sociedade brasileira passará a conviver com um nível de desigualdade de renda corrente mais elevado (reta verde no Gráfico 4).

Pelos dados apresentados, fica evidente que a extinção do auxílio emergencial, do ponto de vista da distribuição de renda, é a pior política a ser adotada. Com a sua eliminação, o índice de Gini que, já em maio, se mostrava 15,2\% maior, tenderia nesse processo de convergência a um nível provável em que a concentração de renda se mostrasse 6,3\% superior (novembro).

${ }^{10}$ Ver alterações na Lei 13.982, de 2020 dadas pelo Decreto n 10.488, de 16 de setembro de 2020.

${ }^{11}$ Uma vez estabelecido que os valores seriam, de fato, reduzidos à metade pelo Decreto $\mathrm{n}^{\circ} 10.488$, de 16 de setembro de 2020, optou-se por não continuar com os cenários $\mathrm{R} \$ 1.000,00 / \mathrm{R} \$ 500,00$ e $\mathrm{R} \$ 800,00 / \mathrm{R} \$ 400,00$, a partir de outubro de 2020. 
Gráfico 4. Evolução do Índice de Gini para a renda pessoal no Brasil, segundo fonte de renda (maio-novembro, 2020)

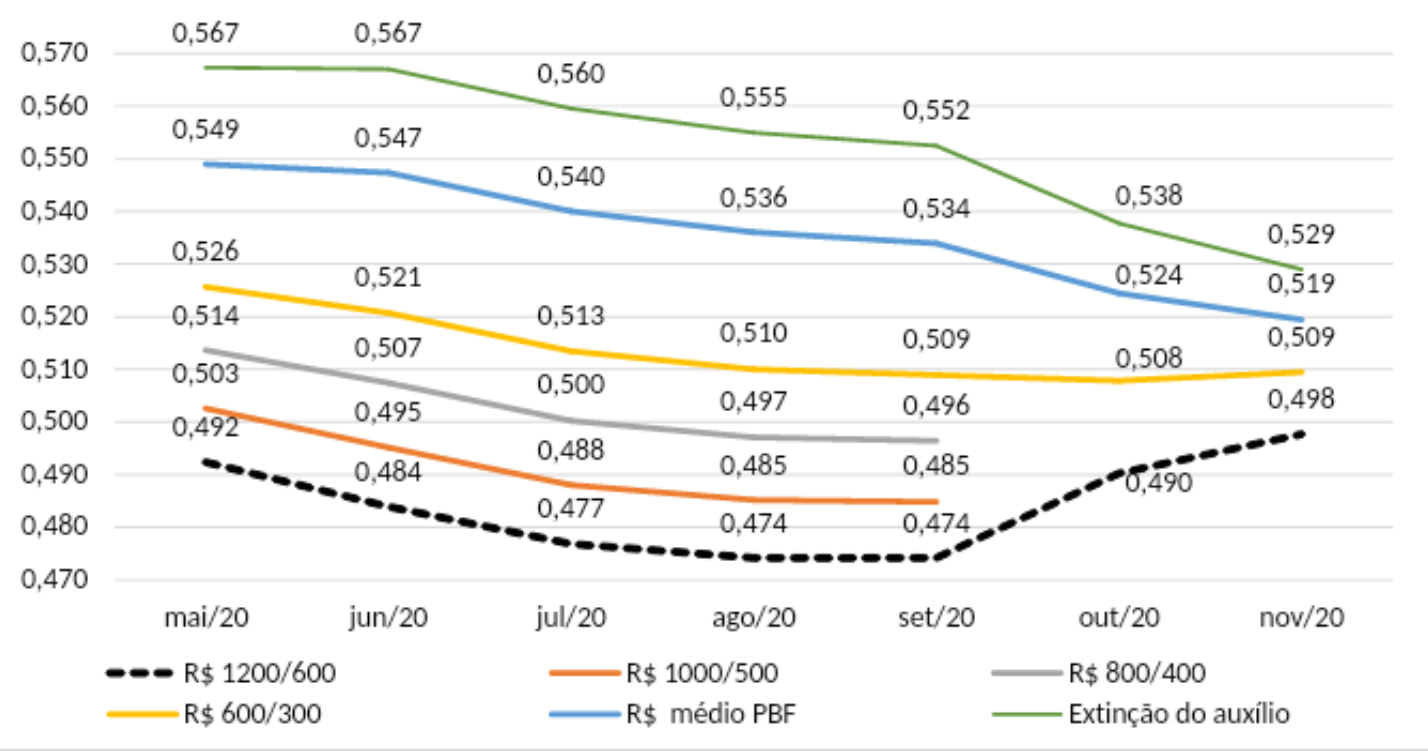

Fonte: PNAD COVID19. Elaboração Própria.

Nota-se, ainda, que uma possível continuidade da tendência de queda da desigualdade, revertida a partir de setembro, de forma independente da política do auxílio emergencial, dependerá do que se observará no mercado de trabalho e em sua estrutura de remuneração no após pandemia. Mais que isso, será condicionada à manutenção do aparato de proteção social permanente, especialmente, daquele que atende as camadas inferiores da distribuição de renda, como é o caso da Previdência Rural, do BPC e, principalmente, do PBF.

\section{Considerações finais}

A desigualdade de renda corrente no país, entre maio e setembro de 2020, caiu por conta do aparato de proteção social permanente e da proteção emergencial, conquistada pela sociedade após intensa disputa no Congresso Nacional.

Em um contexto de severa crise sanitária e socioeconômica, a renda obtida no âmbito do mercado de trabalho não se mostrou um instrumento capaz de equacionar o desafio da elevada concentração da renda corrente no país. Pelo contrário, sua regressividade, em um contexto de elevação da desocupação e do desalento, evidencia que o papel do Estado e as políticas públicas associadas à renda são fundamentais para mitigar os efeitos negativos da crise, inclusive quanto à queda do consumo de bens de primeira necessidade.

Por fim, os dados apontam para uma trajetória bastante provável de elevação do nível da desigualdade decorrente da redução do valor do auxílio e/ou de sua extinção no futuro próximo. A desproteção de significativa parcela da população em 
vulnerabilidade, para além da elevação da desigualdade, certamente trará impactos ainda mais negativos do ponto de vista do empobrecimento da sociedade brasileira.

A lenta recuperação da atividade econômica associada à desestruturação do mercado de trabalho trará desafios para o caminho do país na direção de uma sociedade menos desigual em um futuro pós Covid-19.

\section{Referências}

Brasil (2020a) "Medida Provisória no 937", de 2 de abril de 2020. Disponível em: < http://www.planalto.gov.br/ccivil_03/_Ato20192022/2020/Mpv/mpv937.htm>

Brasil (2020b) "Medida Provisória no 956", de 29 de abril de 2020. Disponível em: $<$ http://www.planalto.gov.br/ccivil_03/_ato20192022/2020/Mpv/mpv956.htm>

Brasil (2020c) "Lei no 13.982", de 2 de abril de 2020. Disponível em: < http://www.planalto.gov.br/CCIVIL_03/_Ato20192022/2020/Lei/L13982.htm>

Folha de São Paulo (2020a) "Guedes diz que está sereno e que reformas são melhor resposta à crise". Disponível em: < https://www1.folha.uol.com.br/mercado/2020/03/guedes-diz-que-estasereno-e-que-reformas-sao-melhor-resposta-a-crise.shtml>

Folha de São Paulo (2020b) "Contra pandemia, governo vai distribuir R 200 para trabalhadores informais". Disponível em: $<$ https://www1.folha.uol.com.br/mercado/2020/03/contra-pandemiagoverno-vai-distribuir-r-200-para-trabalhadores-informais.shtml>

Hoffmann, R. (2009) "Desigualdade da distribuição da renda no Brasil: a contribuição de aposentadorias e pensões e de outras parcelas do rendimento domiciliar per capita". Economia e Sociedade, 18(1), p. 213-231. Disponível em: < https://doi.org/10.1590/S0104-06182009000100007>

IBGE (2020a) "Pesquisa Nacional por Amostra de Domicílios: PNAD COVID19: junho/2020: resultado mensal”. IBGE, Coordenação de Trabalho e Rendimento, Rio de Janeiro, 2020.

IBGE (2020b) "Pesquisa Nacional por Amostra de Domicílios: PNAD COVID19: julho/2020: resultado mensal". IBGE, Coordenação de Trabalho e Rendimento, Rio de Janeiro, 2020. 
IBGE (2020c) "Pesquisa Nacional por Amostra de Domicílios: PNAD COVID19: agosto/2020: resultado mensal”. IBGE, Coordenação de Trabalho e Rendimento, Rio de Janeiro, 2020.

IBGE (2020d) "Pesquisa Nacional por Amostra de Domicílios: PNAD COVID19: setembro/2020: resultado mensal". IBGE, Coordenação de Trabalho e Rendimento, Rio de Janeiro, 2020.

IBGE (2020e) "Pesquisa Nacional por Amostra de Domicílios: PNAD COVID19: outubro/2020: resultado mensal". IBGE, Coordenação de Trabalho e Rendimento, Rio de Janeiro, 2020.

IBGE (2020f) "Pesquisa Nacional por Amostra de Domicílios: PNAD COVID19: novembro/2020: resultado mensal". IBGE, Coordenação de Trabalho e Rendimento, Rio de Janeiro, 2020.

IMF (2020) "A Crisis Like No Other, An Uncertain Recovery". World Economic Outlook Update, June 2020. Disponível em: < https:/www.imf.org/en/Publications/WEO/Issues/2020/06/24/WEOUpdateJu ne2020>

Lerman, R. I.; Yitzhaki, S. (1985) "Income inequality effects by income source: a new approach and applications to the United States", The Review of Economics and Statistics, 67(1), p. 151-156. Disponivel em: < https://doi.org/10.2307/1928447>

Lerman, R. I.; Yitzhaki, S. (1994) "Effects of marginal changes in income sources on U.S. income inequality", Public Finance Quarterly, 22(4), p. 403-417. Disponível em: < https://doi.org/10.1177/109114219402200401>

OECD (2020) "OECD Employment Outlook 2020: Worker Security and the COVID19 Crisis", OECD Publishing, Paris, Jul 2020. 